\title{
Heat Transfer Enhancement through Annular Flow using Rotating Finned Pipe
}

\author{
\{M. A. Yassin, H. M. Abd El-Hameed, M. H. Shedid, Abdel Hamid B.Helali\} ${ }^{*}$
}

\begin{abstract}
The thermal characteristics for the flow through the annulus with inner finned tube under stationary and rotating conditions are experimentally investigated. The experiments are carried out using both unfinned and finned tubes at different rotating speeds range from 0 to $400 \mathrm{rpm}$. The effect of fins number and its heights are studied for the straight fins which used with inner pipe. The Reynolds number ranged from 3x104 to 9x104, while Taylor number ranged from $3 \times 106$ to $11 \times 106$. The results showed an increase of the heat transfer coefficient more than six times for the height of $30 \mathrm{~mm}$ and rotational speeds of $400 \mathrm{rpm}$ at $\operatorname{Re}=6 \times 104$, compared to the case for plain stationary pipe. The rotational speed revealed no effect on the efficiency and effectiveness of the fin. Correlation for Nusslet number and the overall efficiency are obtained.
\end{abstract}

Keywords: Annular flow, Double pipe, rotating inner pipe, heat transfer enhancement.

\section{Nomenclature}

$\begin{array}{ll}\text { A } & \text { Area, } m^{2} \\ \text { B } & \text { Annular gab width, m } \\ \text { D } & \text { Outer diameter of the inner rotating pipe, } \mathrm{m} \\ \mathrm{D} & \text { Inner diameter of the outer pipe, } \mathrm{m} \\ \mathrm{H} & \text { Convection heat transfer coefficient, } \mathrm{w} / \mathrm{m}^{2} \mathrm{k} \\ \mathrm{H} & \text { Fin height, } \mathrm{m} \\ \mathrm{K} & \text { Thermal conductivity of air, W/mK } \\ \mathrm{L} & \text { Effective length of test section, } \mathrm{m} \\ \mathrm{m} & \text { Mass flow rate, Kg/s } \\ \mathrm{N} & \text { Number of fins } \\ \mathrm{N} & \text { Rotational speed of inner pipe, } \mathrm{rpm} \\ \mathrm{Q} & \text { Rate of heat transfer, W } \\ \mathrm{T} & \text { Fin thickness, } \mathrm{m} \\ \mathrm{T} & \text { Temperature, }{ }^{\circ} \mathrm{C} \\ \mathrm{V} & \text { Velocity } \\ \text { Greek Letters } \\ \Delta & \text { Difference } \\ \mu & \text { Dynamic viscosity of air, Pa.s } \\ \mathrm{N} & \text { Kinematic viscosity of air, } \mathrm{m}^{2} / \mathrm{s} \\ \mathrm{P} & \text { Density, Kg } / \mathrm{m}^{3} \\ \Omega & \text { Angular velocity of rotating inner pipe, } \mathrm{rad} / \mathrm{s}\end{array}$

Mechanical Power Engineering Department, Faculty of Engineering, Mattaria, Helwan University, Cairo, 11718, EGYPT. 


\begin{tabular}{ll}
\multicolumn{2}{l}{ Subscripts } \\
A & Air \\
C & Cold \\
F & Fin \\
In & Inlet \\
Out & Outlet \\
S & Surface
\end{tabular}

$\begin{array}{ll}\text { Dimensionless Groups: } \\ \mathrm{NU} & \text { Nusselt number } \\ \mathrm{Re} & \text { Reynolds number } \\ \mathrm{Ta} & \text { Taylor number }\end{array}$

\section{Introduction}

A concentric cylindrical annulus where either the inner or outer cylinder is stationary or rotating are widely used in various mechanical systems such as annular heat exchangers, gas turbines, jet engines, chemical industry, petroleum processing, gas-cooled nuclear reactor, mechanical and chemical mixers and drilling operations in the oil industry. Therefore, the study of forced convection heat transfer in annular passages is interesting for many industrial processes. Accordingly, numerous experimental and theoretical investigations that were initiated from both hydrodynamic and thermal point of views were conducted. Many passive, active and compound heat transfer enhancement techniques for the annular flow are discussed by Léal [1]. Passive techniques does not need any direct contribution of external power [2], while active techniques requires external power input such as mechanical aids, surface vibrators, fluid vibrators, electrostatics, suction and jet impingements [3].

Most passive techniques affect the fluid bulk motion causing swirls and disturbs the actual boundary layer. This operation enhances the heat transfer coefficient as it contributes to increase both the effective surface area and residence time of the flow. This method includes fins with different geometries [4-7], surface finishing [8], fluid additives that give a reasonable change to the physical properties of fluid such as nanofluids [9-10].

The simultaneous use of two or more techniques in the annular channel significantly enhanced the heat transfer greater than that found by either of them when used individually. Various compound techniques that are used to enhance heat transfer in annular channel can be found in literature [4, 11-16]. A lot of work has been performed for heat transfer enhancement on the annular space between two pipes.

Omkar [15] evaluated the heat transfer characteristics data for the helical fins that were installed on the rotating inner tube of double pipe heat exchanger. The laminar flow results showed that the Nusselt number is found to increase up to $64 \%$ at $100 \mathrm{rpm}$ compared to stationary inner tube with helical fins. While the turbulent flow results $\left[\operatorname{Re}=8 \times 10^{4}-1.8 \times 10^{5}\right]$ is evaluated by A-Ziyan [13]. He reported that $\mathrm{Nu}$ is enhanced by a factor of 7.5 at $400 \mathrm{rpm}$ and the ratio of heat transfer to pumping power is increased by a factor of 7.6, compared to the case for plain stationary pipe at $\mathrm{Re}=1.5 \times 10^{5}$. Zhang et al. [7] experimentally investigated the presence of the vortex generator of delta-wing type on the heat transfer characteristics of the helical fins. Heat transfer characteristics enhanced by $87-115 \%$ more than that transferred by the heat exchanger with smooth inner tube.

Fénot [17] used slotted rotating inner cylinder to enhance the convective heat transfer in the entry region of an annular channel. Experiments was conducted for Taylor number from $10^{4}$ to $4 \times 10^{6}$ to reproduce the conditions for air gap of an open four-pole synchronous motor and different correlations are presented. Ranjith [18] carried out an experiment to measure the heat transfer coefficients and pressure drop for twisted tapes inserts double pipe heat 
exchanger. The experimental results revealed that both heat transfer coefficient and pressure drop in the pipe with twisted tape, are higher than those in the plain pipe.

El-Maghlany et al. [19] studied the fluid flow and heat transfer characteristics of double-pipe heat exchanger with rotating inner pipe. The experiments covered a range for rotational speed from 0 to $1000 \mathrm{rpm}$. The effectiveness and NTU number obtained for parallel flow and counter flow arrangement. They found that rotation speed increases NTU and effectiveness values.

The foregoing literature reviews show that there have been no studies focused on the heat transfer performance of an annular space of rotating inner pipe with straight fins. The performance of the rotating fins has a little interest for the researchers. The objective of the present work is to evaluate the effects of using a compound heat transfer augmentation techniques for the flow through the annulus by using the straight fins fixed on a rotated inner pipe on the heat transfer characteristics. Both the efficiency and the effectiveness of the rotated fins are to be investigated.

\section{Experimental Apparatus and Data Reduction}

\subsection{Description of Experimental Setup}

Figure. 1 shows the schematic diagram of the experimental apparatus which is designed for measuring the thermal and hydrodynamic characteristics for the flow through the annular space. The test rig is facilitated with different operating configurations such as rotating speed for inner tube, axial flow speed, number of fins, and height of fins. The system consists of hot and cold air path and test section as shown in Fig. 1.

An electric heater of $9.6 \mathrm{~kW}$ total power (1), located in steel insulated box, was used to increase the supply air temperature. To prevent air leakage between heater section and rotating test section, stuffing box was installed at heater exit. Blower with $3.5 \mathrm{~kW} \mathrm{AC} \mathrm{motor}$ is used to drive atmospheric air through test section. Hot air drawn by air blower of $7.5 \mathrm{~kW}$ pass through the annuals area of the test section.

The test section, Fig. (2), is $1600 \mathrm{~mm}$ length and consists of two concentric pipes. The outer pipes, $150 \mathrm{~mm}$ diameter is made of polyvinyl chloride. In addition, glass wall thermal insulation was used to cover the outer pipe to fulfil the adiabatic condition at the external surface. The inner rotating pipe of $50 \mathrm{~mm}$ diameter, is made of brass. It is supported on two journal bearings, and rotated by variable speed electric motor $3 \mathrm{HP}$.

The air velocity is measured by using standard pitot tube connected to digital micromanometer (YOKOGAWA 2655-11E). Thermocouple Type $\mathrm{k}$ is used to measure air temperatures. Two thermocouples are located one before and one after the test section to evaluate the average air temperatures in the annular gap at different depths using thermocouples provided with two special probes. The surface temperatures for the inner rotating pipe and fins were measured at the midway between the inlet and outlet of the test section with six thermocouples (type k). the location was selected where the errors due to axial heat gradients are considered minimum at midway of test section. The slip rings, shown in Fig. 2, with graphite connectors was used to transmit the thermocouple signals of the rotating pipe to the stationary part. All thermocouples were connected through selector switch to a digital thermometers readout unit with a resolution of $0.1^{\circ} \mathrm{C}$. In addition, the speed of rotation of inner pipe was measured by hand held photo tachometer. The experimental program and the range of experimental conditions are listed in Table 1.

Table 1 Experimental program and experimental conditions.

\begin{tabular}{|l|l|l|l|}
\hline \multicolumn{2}{|l|}{ Straight fin characteristics, } & \multirow{2}{*}{ Examined tube } & $\mathrm{n}(\mathrm{rpm})$ \\
\hline No. of fins & Height of fins $(\mathrm{mm})$ & & \\
\hline 0,2 and 4 & $0,10,20$ and 30 & Unfinned and Straight finned & $0,200,250,300,350,400$ \\
\hline
\end{tabular}


The experimental procedures for all runs started by setting the air flow inside the inner pipe and its rate of heating to provide adequate heating of the inner pipe wall. For each run, the prescribed flow rate through the annulus and the speed of rotation was adjusted. Then, the system was allowed to reach thermal equilibrium where all measurements were made under steady state conditions.

\subsection{Data Reduction Technique}

The heat transfer coefficient in the test section, $h$, was determined by a simple energy balance equations as follows:

$$
\begin{aligned}
& Q=m \cdot C_{p}\left(T_{a, \text { out }}-T_{a, \text { in }}\right) \\
& Q=h\left(A_{s} \Delta T_{s}+A_{f} \Delta T_{f}\right)
\end{aligned}
$$

In equation (2), $\Delta T_{s}=T_{s}-T_{c m}$ and $\Delta T_{f}=T_{f}-T_{c m}$

where $T_{s}$ and $T_{f}$ are the average temperature of pipe and fins, respectively, whereas $T_{c m}$ is the average fluid bulk temperature.

$$
h=\frac{m \cdot C_{p}\left(T_{a, o u t}-T_{a, i n}\right)}{\left(A_{s} \Delta T_{S}+A_{f} \Delta T_{f}\right)}
$$

The evaluated heat transfer coefficient as well as the physical properties are used to calculate the main four principal dimensionless parameters; Reynolds, Taylor and Nusselt numbers as follows.

$$
\begin{aligned}
& N u=\frac{h D_{h}}{K} \\
& R_{e}=\frac{V_{a} D_{h}}{v}
\end{aligned}
$$

where the hydraulic diameter $\mathrm{D}_{\mathrm{h}}$ that characterize the geometry of the annular space is defined for unfinned and finned pipes as:

$$
\begin{array}{ll}
D_{h}=D-d & \text { for unfinned pipe } \\
D_{h}=\frac{4\left(\frac{\pi}{4}\left(D^{2}-d^{2}\right)-n_{f} H t\right)}{\pi(D+d)+2 n_{f} H} & \text { for finned pipe }
\end{array}
$$

Taylor number (Ta) which is a dimensionless quantity that indicate the importance of centrifugal "forces" or so-called inertial forces due to rotation of a fluid about an axis, relative to viscous forces.

$$
T_{a}=\frac{2 \omega^{2} R_{1}^{2} b^{3}}{v^{2}\left(R_{1}+R_{2}\right)}
$$

where the inner tube angular velocity is defined by: $\omega=2 \pi n / 60, b=(D-d) / 2$ and $v$ is kinematic viscosity of air.

The uncertainty analysis is conducted according to the method described by Kline and McClintock [20] and modified by Moffat [21]. The uncertainty in the reported experimental values of Reynolds, Taylor and Nusselt numbers and were estimated to be about $6.178 \%$, $5.67 \%$ and $6.28 \%$, respectively. 


\section{Result and Discussion}

The presented experimental tests were target to cover the stationary and rotating finned/unfinned inner tube operation modes; Reynolds number ranged from $3 \times 10^{4}$ to $9 \times 10^{4}$ and Taylor number ranged from $3 \times 10^{6}$ to $11 \times 10^{6}$. Six straight finned pipes with different fin numbers and heights are considered and compared with the plain pipe under stationary and rotating conditions.

A comparison study between the experimental $\mathrm{Nu}$ and the correlation developed by Gnielinski [22] for heat transfer in stationary annular channel to ascertain the reliability and accuracy of the present work was conducted. The validation revealed that most of experimental results are greater and lower than the predicted Nusselt number for Gnielinski correlation within $13 \%$ as seen in Fig. 3. Hence, the present experimental apparatus, can be used to study the thermal characteristics produces reliable data. Details discussion of the effect of different characteristic parameters will be conducted in the following subsections.

\subsection{Effect of Rotational Speed}

The rotation speed effect on the heat transfer process in the annular space are illustrated in Fig. 4 for unfinned inner pipe, (Fig. 5a-c) for inner pipe with two fins and (Fig. 6a-c) for inner pipe with four straight fins. Nusselt number are presented as a function of Reynolds number for different rotation speeds $(0,200,250,300,350$ and $400 \mathrm{rpm})$ of inner pipe. It is clear that $\mathrm{Nu}$ increases as either $\mathrm{Re}$ or the rotational speed of the inner pipe increases in all cases of stationary or rotating inner pipe with or without straight fins attached on the pipe surface.

Figure 4 shows that in the case of inner unfinned pipe, Nu increases by 50\%, 89\%, 130\%, $153 \%$ and $167 \%$ at inner pipe rotational speeds of 200, 250, 300, 350 and $400 \mathrm{rpm}$ compared to $\mathrm{Nu}$ for stationary pipe at $\mathrm{Re}=8 \times 10^{4}$. These enhancement may be attributed to what is named Taylor vortices [23] that is formed afterward the entrance region. These vortices disturb the regular development of the boundary layers and enhance the convection heat transfer coefficients of the annular boundaries. The turbulent kinetic energy increased with the rotation speed increases [24]. Consequently, this is resulting in a considerable enhancement of momentum and heat transfer.

Additional disturbances and turbulence produced due to the increase of inner finned tube helped to enhance the heat transfer rate. Hence, the $\mathrm{Nu}$ enhanced by about $213 \%, 192 \%$ and $173 \%$ at two fins with height of 10, 20 and $30 \mathrm{~mm}$, respectively, as shown in Figure 5a-c at the speed increases from 0 to $400 \mathrm{rpm}$ at $\mathrm{Re}=6 \times 10^{4}$. In addition, $\mathrm{Nu}$ enhances by about $201 \%, 185 \%$ and $182 \%$ at four fins with height of 10, 20 and $30 \mathrm{~mm}$, respectively (Fig. 6a-c).

\subsection{Effect of Inner Pipe Geometry}

\section{a) Fin height, (H).}

Figures 7 and 8 provide a comparison between the heat transfer characteristics in the annular space for unfinned and finned tubes with fin height of 10, 20 and $30 \mathrm{~mm}$ at rotational speeds of 0 and $400 \mathrm{rpm}$ and four fins. Generally, Nusselt number Nu increases as the straight fins height increases and the minimum values of $\mathrm{Nu}$ is found at unfinned tube. The heat transfer enhancement is due to the increase in the heat transfer area beside the extra disturbances and turbulence caused by the straight fins in the annular space as mentioned above. For example, under the stationary conditions $\mathrm{Nu}$ increases by $73 \%, 98 \%$ and $118 \%$ at $\operatorname{Re}=6 \times 10^{4}$ for straight fins height of 10, 20 and $30 \mathrm{~mm}$, respectively, compared to $\mathrm{Nu}$ for unfinned pipe. On the other hand when inner pipe rotates at $400 \mathrm{rpm}$ as shown in Fig. 8, Nu increases by 104\%; $116 \%$ and $142 \%$ at $\operatorname{Re}=6 \times 10^{4}$, for straight fins height of 10,20 and $30 \mathrm{~mm}$, respectively, relative to $\mathrm{Nu}$ for unfinned pipe that rotates at the same speed. 


\section{b. Number of fins $\left(\mathbf{n}_{\mathbf{f}}\right)$}

Figures 9 and 10 provide a comparison between the heat transfer characteristics in the annular space for cases of unfinned and finned pipe with 2 and 4 fins of equal $30 \mathrm{~mm}$ height and rotational speeds of 0 and $400 \mathrm{rpm}$. The annular space without fins revealed lower $\mathrm{Nu}$ compared to all cases of finned tube. Nusselt increases as the straight fins number increases.

As a result of heat transfer surface area increases as well as the additional disturbance and turbulence caused by adding more fins.

Figure 9 shows the effect of straight fins number in the annular space under stationary conditions. $\mathrm{Nu}$ increases by $100 \%$ and $118 \%$ at $\mathrm{Re}=6 \times 10^{4}$ for two fins and four fins, respectively, relative to $\mathrm{Nu}$ for plain pipe. On the other hand, when inner pipe rotates at 400 $\mathrm{rpm}$ as shown in Fig. 10, $\mathrm{Nu}$ increases by $112 \%$ and $144 \%$ at $\mathrm{Re}=6 \times 10^{4}$, for two fins and four fins, respectively, relative to $\mathrm{Nu}$ for plain pipe that rotates at the same speed.

\subsection{Effect of Taylor Number}

The effect of Taylor number Ta on the heat transfer is illustrated in Figs. 11 and 12 for the unfinned pipe and for the four fins of $30 \mathrm{~mm}$ height, respectively. Figure 11 at $\operatorname{Re}=6-8 \times 10^{4}$ while Fig. 12 is at $\mathrm{Re}=4-6 \times 10^{4}$.

It is clear that the $\mathrm{Nu}$ increases with increasing $\mathrm{Ta}$ for both cases. For example, as Taylor number increases up to $3 \times 10^{6}$ the Nu number is enhanced by about $160 \%$ for unfinned pipe at all used range of $\operatorname{Re}\left(6-8 \times 10^{4}\right)$, while it is increased by 150,161 and $170 \%$ for Reynolds number 4,5 and $6 \times 10^{4}$, respectively. These values give an indications that the effect of Ta on the heat transfer by convection has an equal order of magnitude for finned and unfinned tubes. For each case, higher Reynolds number is responsible of generating higher rate of disturbances and turbulence which consequently increase the convection heat transfer coefficient, as well as Nusselt number. However, the overall turbulent was found to be of greater magnitude for higher Taylor number due to the overcoming of the rotating fluid inertia (centrifugal force) over its viscous force.

\section{Fins Performance}

The performance of the rotating fins is assessed, as in stationary fins, using both the fin overall efficiency $\eta_{\mathrm{o}}$ and fin overall effectiveness $\varepsilon_{0}$ [22]. These two parameters depend on different physical and thermal parameters of fins such as corrected fin length $l_{C}$, convection heat transfer coefficient $h$, thermal conductivity of material $k$ and fin profile area $A_{p}$. The relation between overall fin effectiveness and efficiency with $l_{c}{ }^{3 / 2}\left(h / k A_{p}\right)^{1 / 2}$ in the annulus at various rotational speeds is shown in Figs. (13-14), respectively.

Figure (13) presents the overall efficiency $\eta_{\mathrm{o}}$ as a function of $l_{c}{ }^{3 / 2}\left(h / k A_{p}\right)^{1 / 2}$. It is clearly seen that the overall efficiency $\eta_{\mathrm{o}}$ decrease with the increase of the parameter $l_{c}^{3 / 2}(h /$ $\left.k A_{p}\right)^{1 / 2}$, at any rotational speed, fin number, and fin height. The rate of efficiency decreasing is higher as fin number increase. However, as fin height decrease the overall efficiency reaches its higher value.

the overall effectiveness $\varepsilon_{\mathrm{o}}$ as a function of $l_{c}^{3 / 2}\left(h / k A_{p}\right)^{1 / 2}$ is shown in Figure (14). It is clearly indicated that $\varepsilon_{0}$ decreases with the parameter $l_{c}^{3 / 2}\left(h / k A_{p}\right)^{1 / 2}$ increases for all operating conditions, any fin numbers or fin heights. The overall effectiveness $\varepsilon_{\mathrm{o}}$ both two and four fins of heights $10 \mathrm{~mm}$ remains unchanged and have values of 1.27 and 1.51 for $\mathrm{n}_{\mathrm{f}}=2$ and 4 fins, respectively. Because of $(\varepsilon>2)$ is used as a criterion to justify the implementation of fins [22], four fins with heights equals to $20 \mathrm{~mm}$ or more are significant in use. 


\section{Correlation of Heat Transfer}

The average heat transfer data in the annular channel for finned inner pipe as presented by Nusselt number are correlated in terms of Reynolds number, Prandtl number, Taylor number, number of fins and the geometrical properties of the fins $(\mathrm{H} / \mathrm{b})$. All data of stationary cases are fitted by a single correlation with correlation coefficient of 0.83 as given by Eq. (10). On the other hand, the data for rotating cases are fitted with correlation factors of 0.92 as given in Eq. (11).

$$
\begin{aligned}
& N u_{s t}=0.107(R e)^{0.723}(\operatorname{Pr})^{0.4}\left(n_{f}\right)^{0.1873}(H / b)^{0.276} \\
& N u_{r o t}=59 \times 10^{-6}(R e)^{0.67}(P r)^{0.4}(T a)^{0.56}\left(n_{f}\right)^{0.12}(H / b)^{0.15} \\
& \eta_{0}=1-\frac{1.0467 * n_{f} * \frac{H}{b}}{0.588 * n_{f} * \frac{H}{b}+1.0564} *\left[1-\frac{\tanh \left(m l_{c}\right)}{m l_{c}}\right]
\end{aligned}
$$

Eqs. (10) and (11) are valid for Re range from $3 \times 10^{4}$ to $9 \times 10^{4}$ and for Eqs.(12) Taylor number range from $2.7 \times 10^{6}$ to $10.8 \times 10^{6}$, number of fins are 2 and 4 and $\mathrm{H} / \mathrm{b}$ from 0.2 to 0.6. A comparison between the experimental and predicted Nusselt numbers can be found in Fig. (15). It is shown that the correlations is capable to predict the Nusselt number with a maximum error of $\pm 17 \%$ of the experimental values. Fig.(16) shows a comparison between the experimental and predicted overall efficiency, at which the maximum error of $\pm 3 \%$ was found.

\section{Conclusion}

The presented work result of investigating the heat transfer data in concentric annular flow with inner unfinned or finned pipe under stationary and rotating conditions are $3 \times 10^{4}-$ $9 \times 10^{4}$ for axial Reynolds number, $3 \times 10^{6}-11 \times 10^{6}$ for Taylor number, revealed the following main outcomes and conclusions:

- Nusselt number is found to be proportional with axial Re, Ta, fin height and number of fins.

- $\mathrm{Nu}$ is enhanced by about $160 \%$ at inner unfinned pipe rotational speeds of $400 \mathrm{rpm}$ compared to $\mathrm{Nu}$ for stationary case while it is enhanced by about $213 \%$ at the speed increases from 0 to $400 \mathrm{rpm}$ at $\operatorname{Re}=6 \times 10^{4}$ for two fins.

- $\mathrm{Nu}$ increases $115 \%$ at $\mathrm{Re}=6 \times 10^{4}$ for four straight fins height of $30 \mathrm{~mm}$, respectively, under stationary conditions relative to $\mathrm{Nu}$ for unfinned pipe.

- Taylor number increases from 0 to $4 \times 10^{6}$, the ratio of rotating $\mathrm{Nu}$ to stationary $\mathrm{Nu}$ for the same pipe increases by $52 \%$ and $75 \%$ at $\mathrm{Re}=6 \times 10^{4}$ for unfinned and finned tubes.

- The highest rate of heat transfer was achieved at four straight fins of $30 \mathrm{~mm}$ height that rotates at $400 \mathrm{rpm}$ where $\mathrm{Nu}$ increased by 5.5 times $\mathrm{Nu}$ for plain stationary annular space at $\operatorname{Re}=6 \times 10^{4}$.

- The two and four fins of height equal $10 \mathrm{~mm}$ have a higher efficiency for all rotating speeds while four fins with heights equals to $20 \mathrm{~mm}$ or more are recommended to use as it provide larger effectiveness.

- All data of stationary cases are fitted by a single correlation with correlation coefficient of 0.83 as given by Eq. (10). On the other hand, the data for rotating cases are fitted with correlation factors of 0.92 as given in Eq. (11). Eqs. (10) and (11) are valid for Re range from $3 \times 10^{4}$ to $9 \times 10^{4}$ and for Eqs.(12) Taylor number range from $2.7 \times 10^{6}$ to $10.8 \times 10^{6}$, number of fins are 2 and 4 and $\mathrm{H} / \mathrm{b}$ from 0.2 to 0.6 . 


\section{References}

[1] Léal, L., Miscevic, M., Lavieille, P., Amokrane, M., Pigache, F., Topin, F., Nogarède, B., Tadrist, L., (2013), "An overview of heat transfer enhancement methods and new perspectives: Focus on active methods using electroactive materials.", International Journal of Heat and Mass Transfer, 61, 505-524.

[2] Dewan, P. Mahanta, K. Sumithraju, P. Kumar, Review of passive heat transfer augmentation techniques, Proc. Inst. Mech. Eng., Part A: J. Power Energy 218 (7) (2004) 509-527.

[2] Chen, K. Ho, Y.A. Abakr, A. Chan, (2016) Fluid dynamics and heat transfer investigations of swirling decaying flow in an annular pipe Part 1: review, problem description, verification and validation, International Journal of Heat and Mass Transfer, 97, 1029-1043.

[3] Liao, Q., Xin, M., (2000), “Augmentation of convective heat transfer inside tubes with three-dimensional internal extended surfaces and twisted-tape inserts". Chemical Engineering Journal, 78, 95-105.

[4] Hosny Z. Abou-Ziyan, Abdel Hamid B. Helali, Mohamed Y.E. Selim, (2016), Enhancement of forced convection in wide cylindrical annular channel using rotating inner pipe with interrupted helical fins, International Journal of Heat and Mass Transfer, 95, 996-1007.

[5] Nagarani, N., Mayilsamy, K., Murugesan, A., Kumar, G. S., (2014), Review of utilization of extended surfaces in heat transfer problems. Renewable and Sustainable Energy Reviews, 29, 604-613.

[6] Zhang, L., Du, W., Wu, J., Li, Y., Xing, Y. 2012. Fluid flow characteristics for shell side of double-pipe heat exchanger with helical fins and pin fins. Experimental thermal and fluid science, 36, 30-43.

[7] P. Champagne, A. Bergles, Development and testing of a novel, variable roughness technique to enhance, on demand, heat transfer in a single-phase heat exchanger, $\mathrm{J}$. Enhanced Heat Transfer 5 (2001) 341-352.

[8] M. H. Shedid. Computational heat transfer for nanofluids through an annular tube. International Conference on Heat Transfer and Fluid Flow (HTFF'14), Prague, Czech Republic, August 11-12, 2014.

[9] M. Elsebay, I. Elbadawy, M.H. Shedid, M. Fatouh, (2016), Numerical resizing study of $\mathrm{A} 12 \mathrm{O} 3$ and $\mathrm{CuO}$ nanofluids in the flat tubes of a radiator, Applied Mathematical Modelling, Volume 40, Issues 13-14, Pages 6437-6450.

[10] Narrein, K., Mohammed, H. (2013), "Influence of nanofluids and rotation on helically coiled tube heat exchanger performance". Thermochimica Acta, 564, 13-23.

[11] C. Woei, Y. Lirng, S. Dar-Wei, (2009), "Jet-array impingement heat transfer in a concentric annular channel with rotating inner cylinder", International Journal of Heat and Mass Transfer, 52, 1254-1267.

[12] Shyy Woei Chang, Wei Ling Cai, Ruo Sin Syu, (2016), "Heat transfer and pressure drop measurements for tubes fitted with twin and four twisted fins on rod", Experimental Thermal and Fluid Science, 74, 220-234.

[13] Shyy Woei Chang, Kuo Ching Yu, Kuan-Chiea Huang, (2017) Thermal performances of tubular flows enhanced by twin and four spiky twisted fins on rod, Applied Thermal Engineering, 112, 45-60.

[14] Shewale Omkar, M., Mane Pravin, A., Gazge Sajid, A. H. \& Pasanna Pradeep, A., (2014), "Experimental Investigation of Double-Pipe Heat Exchanger with Helical Fins on the Inner Rotating Tube.", International Journal of Research in Engineering and Technology, 7, 98-102.

[15] N.-S. Liu, X.-Y. Lu, (2005), "Large eddy simulation of turbulent flows in a rotating concentric annular channel”, Int. J. Heat Fluid Flow 26 (3), 378-392. 
[16] Fénot, M., Bertin, Y., Dorignac, E. \& Lalizel, G., (2011), "A review of heat transfer between concentric rotating cylinders with or without axial flow". International journal of thermal sciences, 50, 1138-1155.

[17] Ranjith, K. Shaji, (2016), "Numerical Analysis on a Double Pipe Heat Exchanger with Twisted Tape Induced Swirl Flow on Both Sides", Procedia Technology, 24, 436-443

[18] El-Maghlany, W., Eid, E., Teamah, M. \& Shahrour, I., (2012), "Experimental study for double pipe heat exchanger with rotating inner pipe". Int J Adv Sci Tech Res Issue, 4, 507-517.

[19] Kline, S. \& McClintock, F., (1953), "Describing Uncertainties in Single-Sample Experiments", Mechanical Engineering, Vol. 75.

[20] Moffat, R. J. 1988. Describing the uncertainties in experimental results. Experimental thermal and fluid science, 1, 3-17.

[21] Incropera, F. P., DeWitt, D. P., Bergman, T. L. and Lavine, A. S. (2007). Fundamentals of Heat and Mass Transfer. Hoboken, Wiley.

[22] J. Kaye, E. Elgar, Modes of adiabatic and diabatic fluid flow in an annulus with an inner rotating cylinder, Trans. ASME J. Heat Transfer 80 (1958) 753-765.

[23] Rothe, T. \& Pfitzer, H. 1997. The influence of rotation on turbulent flow and heat transfer in an annulus between independently rotating tubes. Heat and mass transfer, 32, 353-364. 


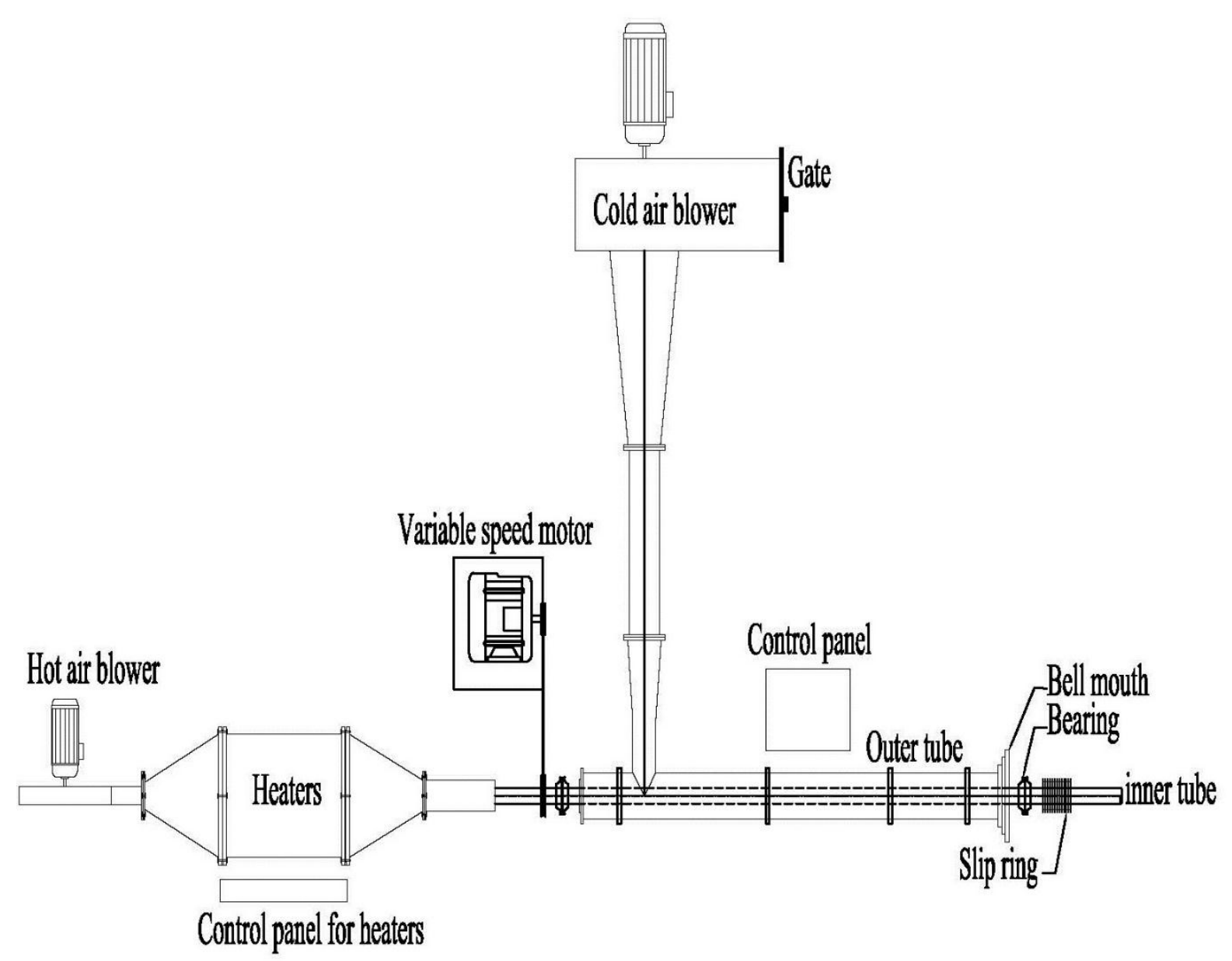

Fig. 1. Schematics of the experimental apparatus.

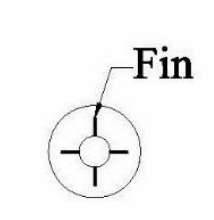

SEC(A-A)

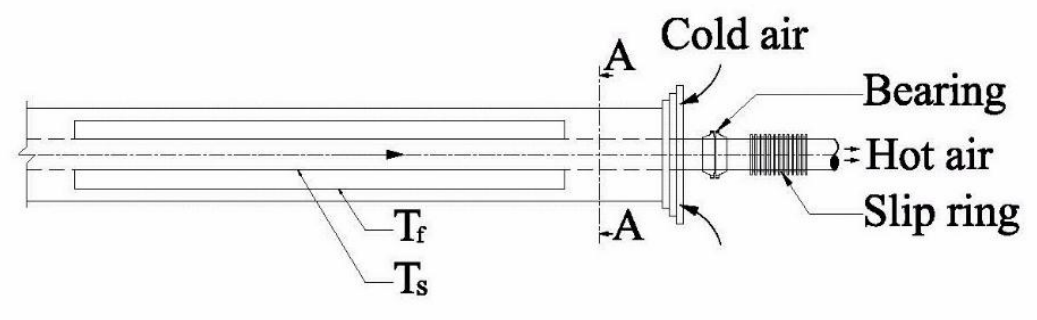

Fig. 2. Test section. 


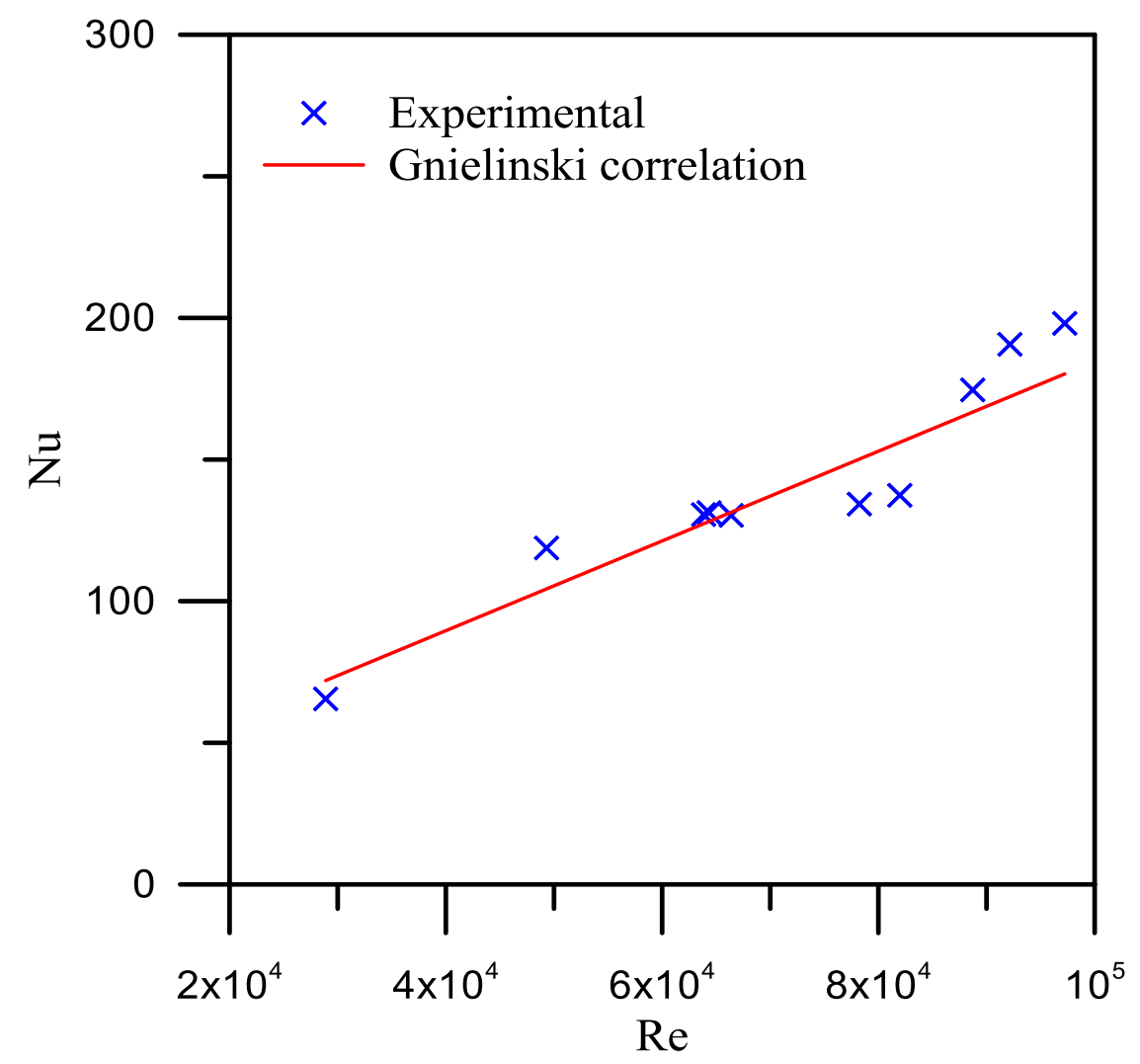

Fig. 3. Comparison between experimental and theoretical Nusselt number.

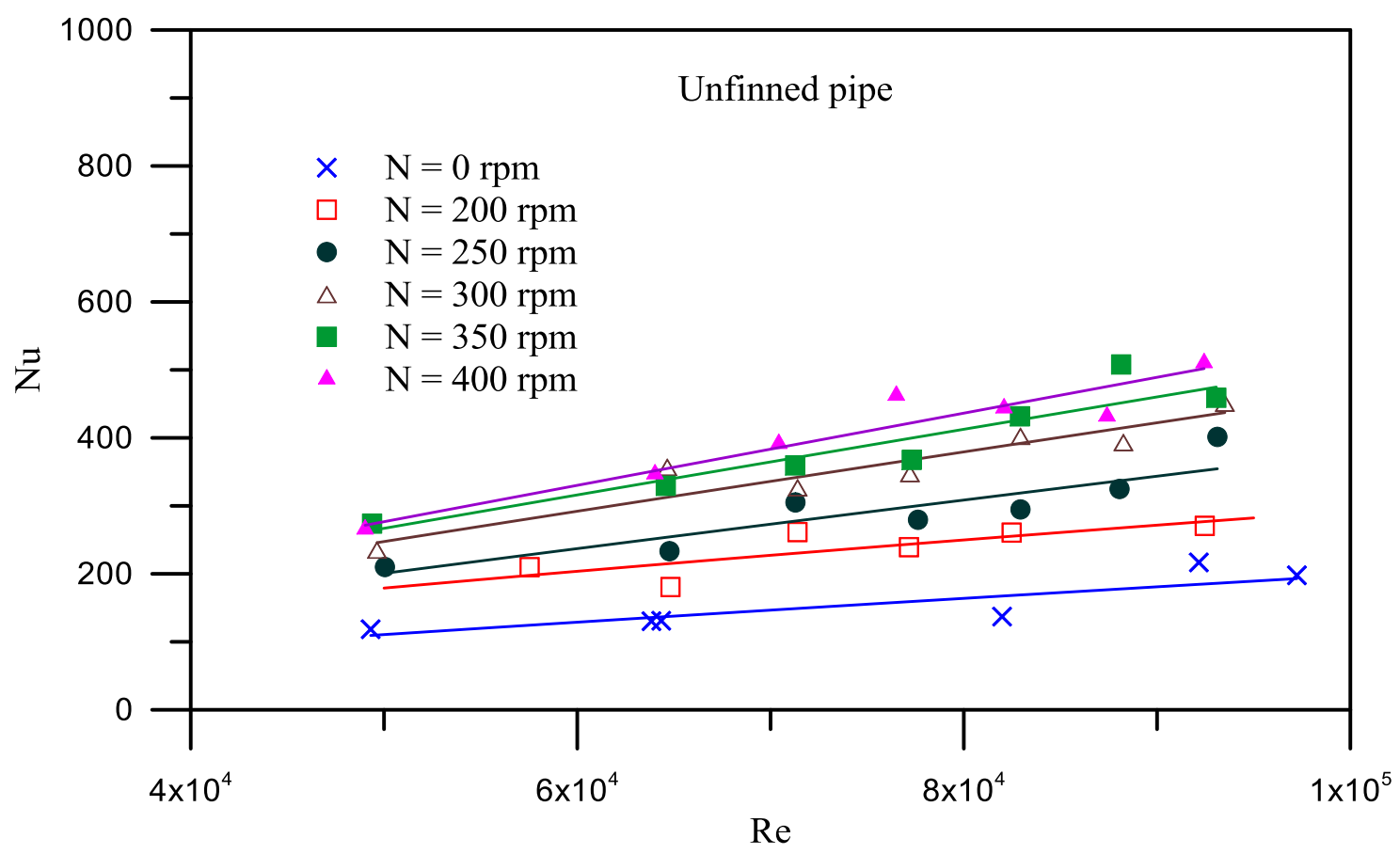

Fig. 4. Variation of Nusselt number with Reynolds number for unfinned pipe. 

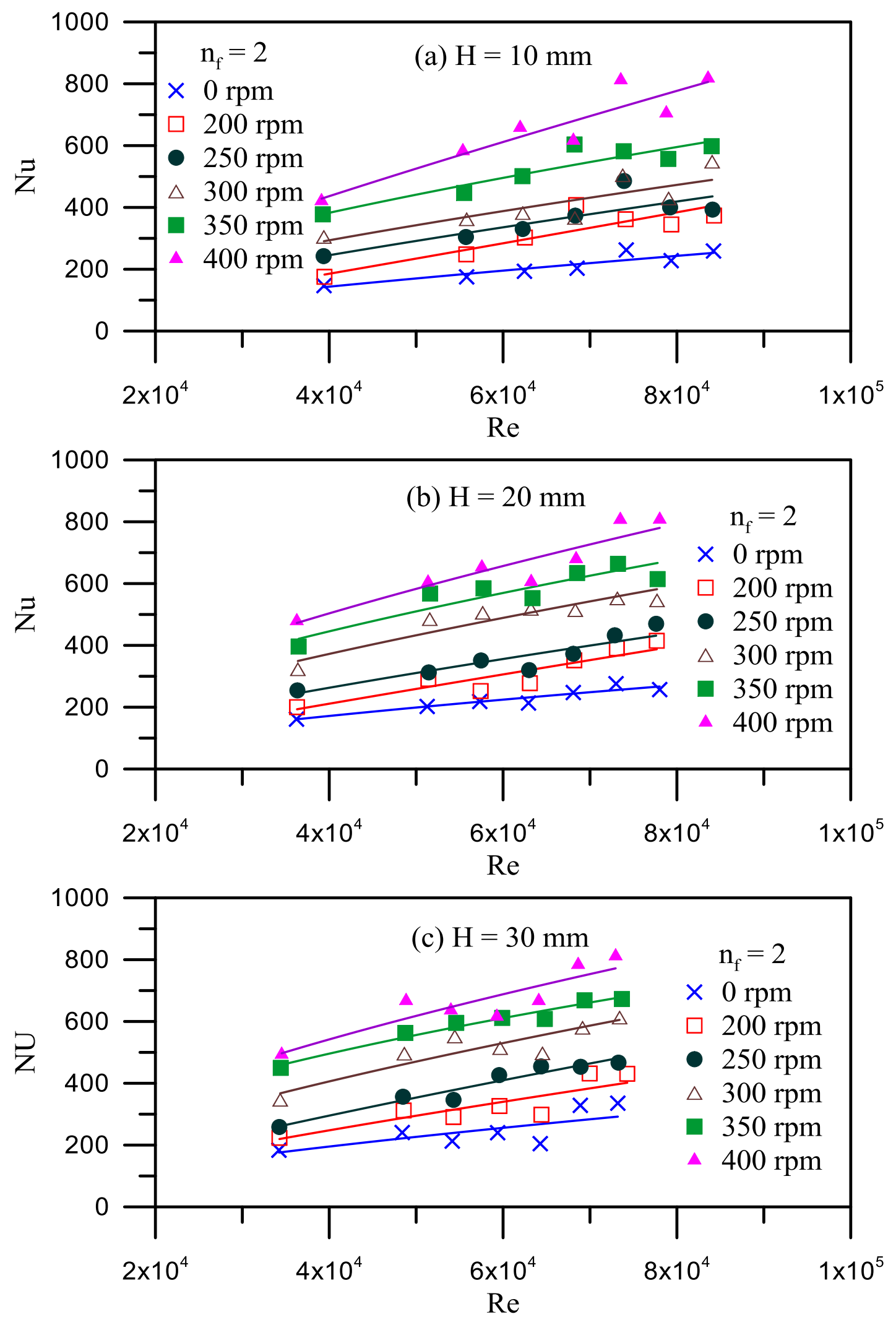

Fig. 5. Variation of Nusselt number with Reynolds number at different rotational speeds for 2 fins; a) $H=10 \mathrm{~mm}, b) H=20 \mathrm{~mm}$ and c) $H=30 \mathrm{~mm}$. 

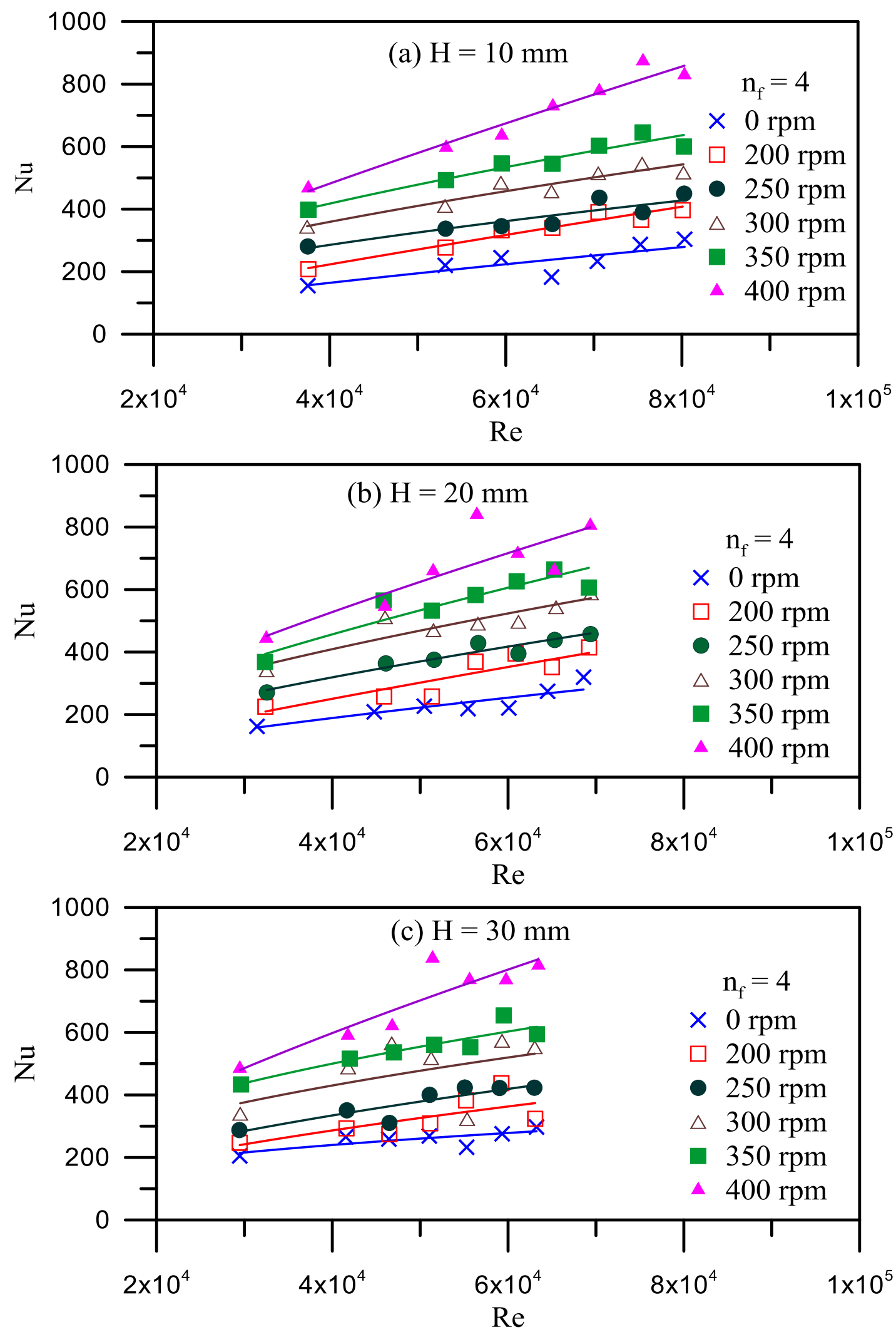

Fig. 6. Variation of Nusselt number with Reynolds number at different rotational speeds for 4 fins; a) $H=10 \mathrm{~mm}$, b) $H=20 \mathrm{~mm}$ and c) $H=30 \mathrm{~mm}$. 


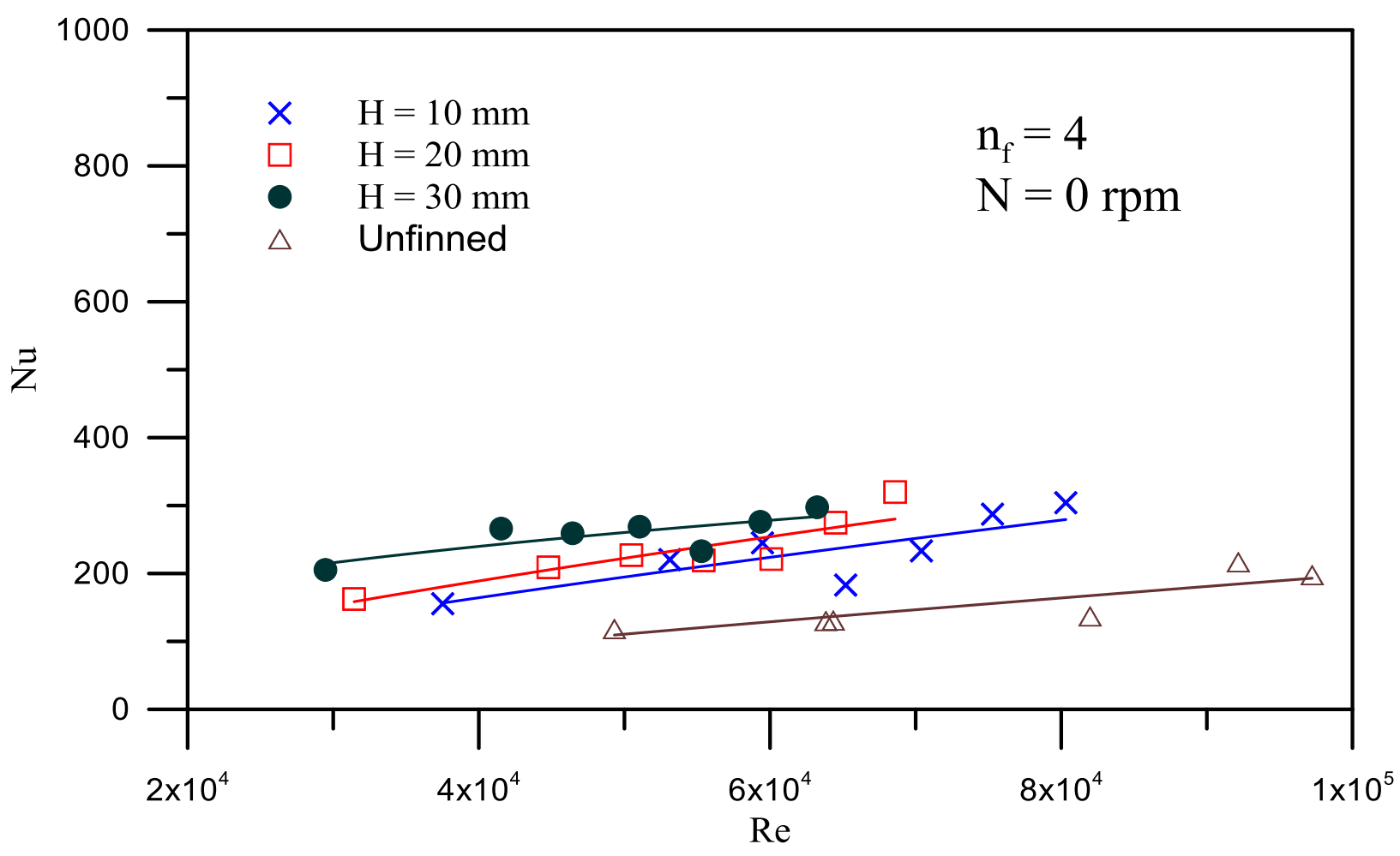

Fig. 7. Nusselt number variation with Reynolds number for 4 fins and 0 rpm.

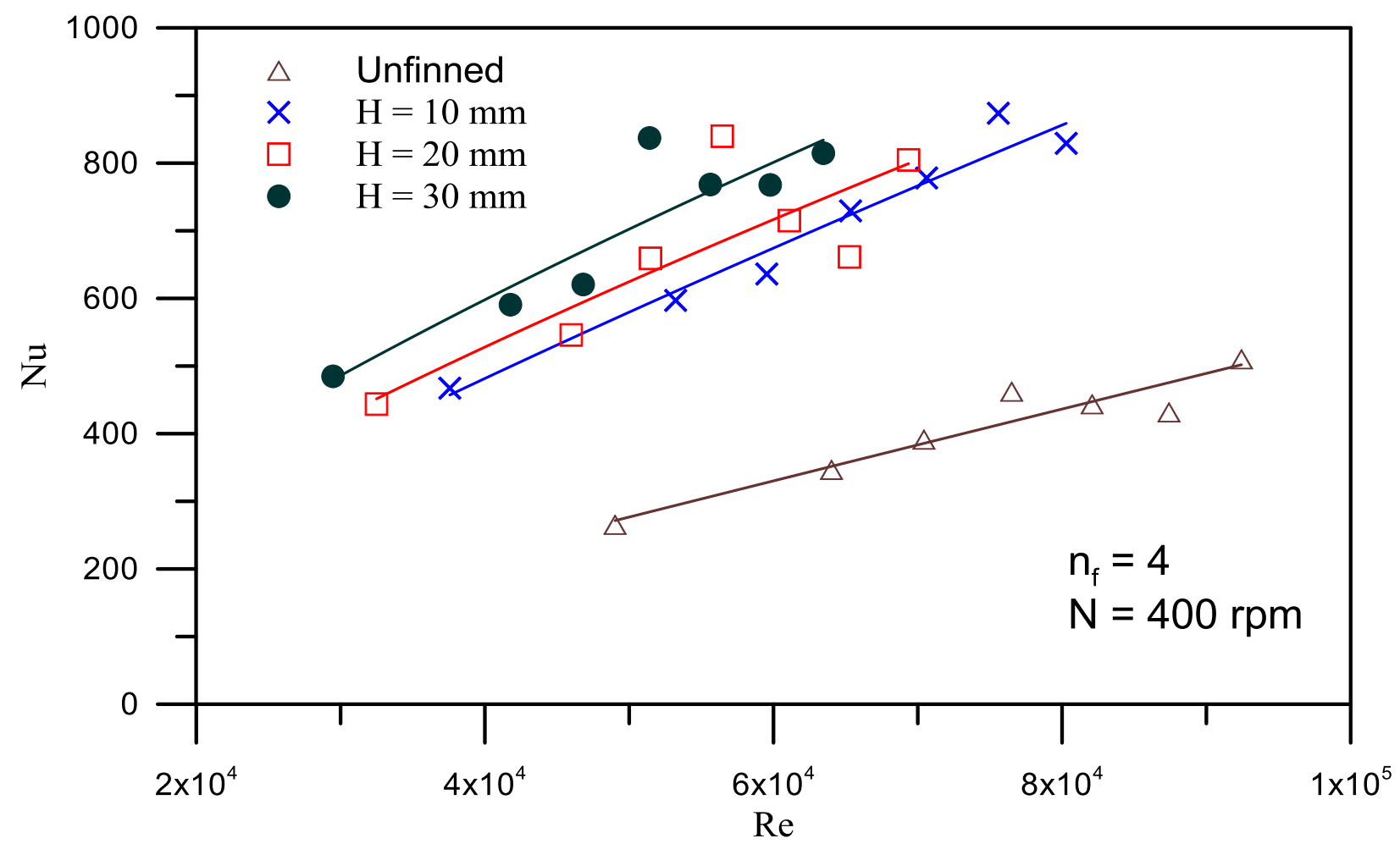

Fig. 8. Nusselt number variation with Reynolds number for 4 fins and 400 rpm. 


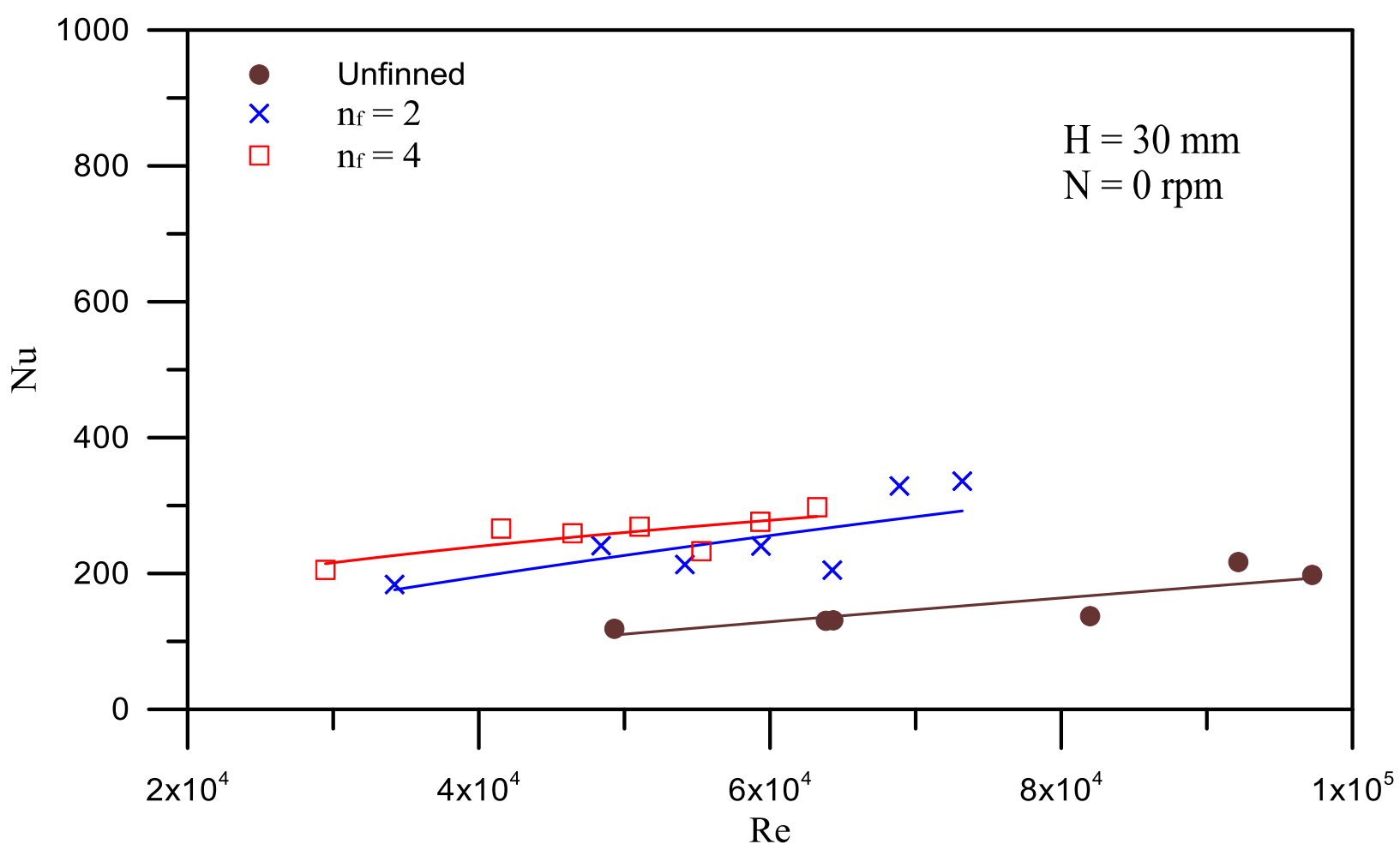

Fig. 9. Nusselt number change with Reynolds number at different fin numbers for $30 \mathrm{~mm}$ fins height and $0 \mathrm{rpm}$.

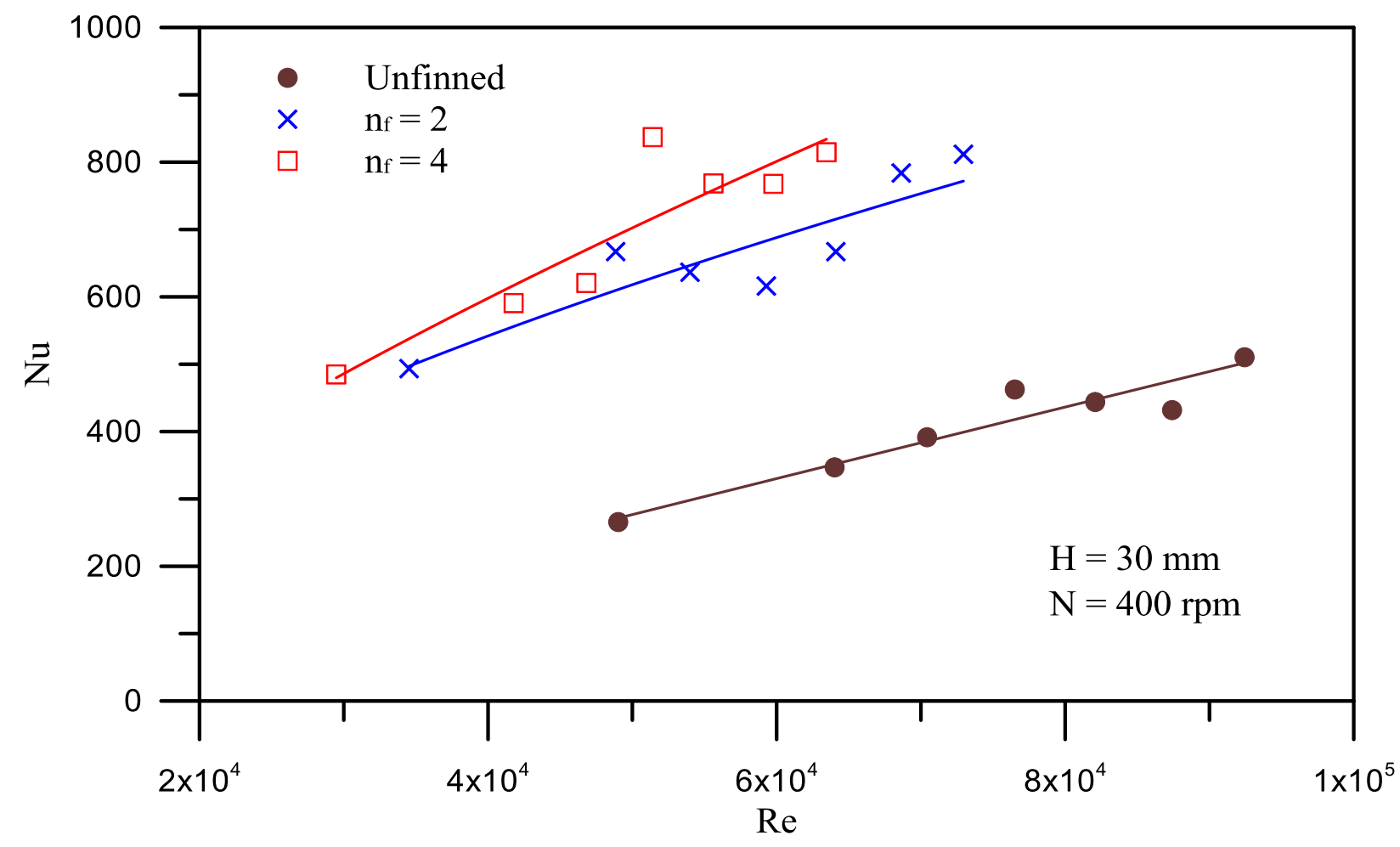

Fig. 10. Nusselt number variation with Reynolds number at different fin numbers for $30 \mathrm{~mm}$ fins height and $400 \mathrm{rpm}$. 


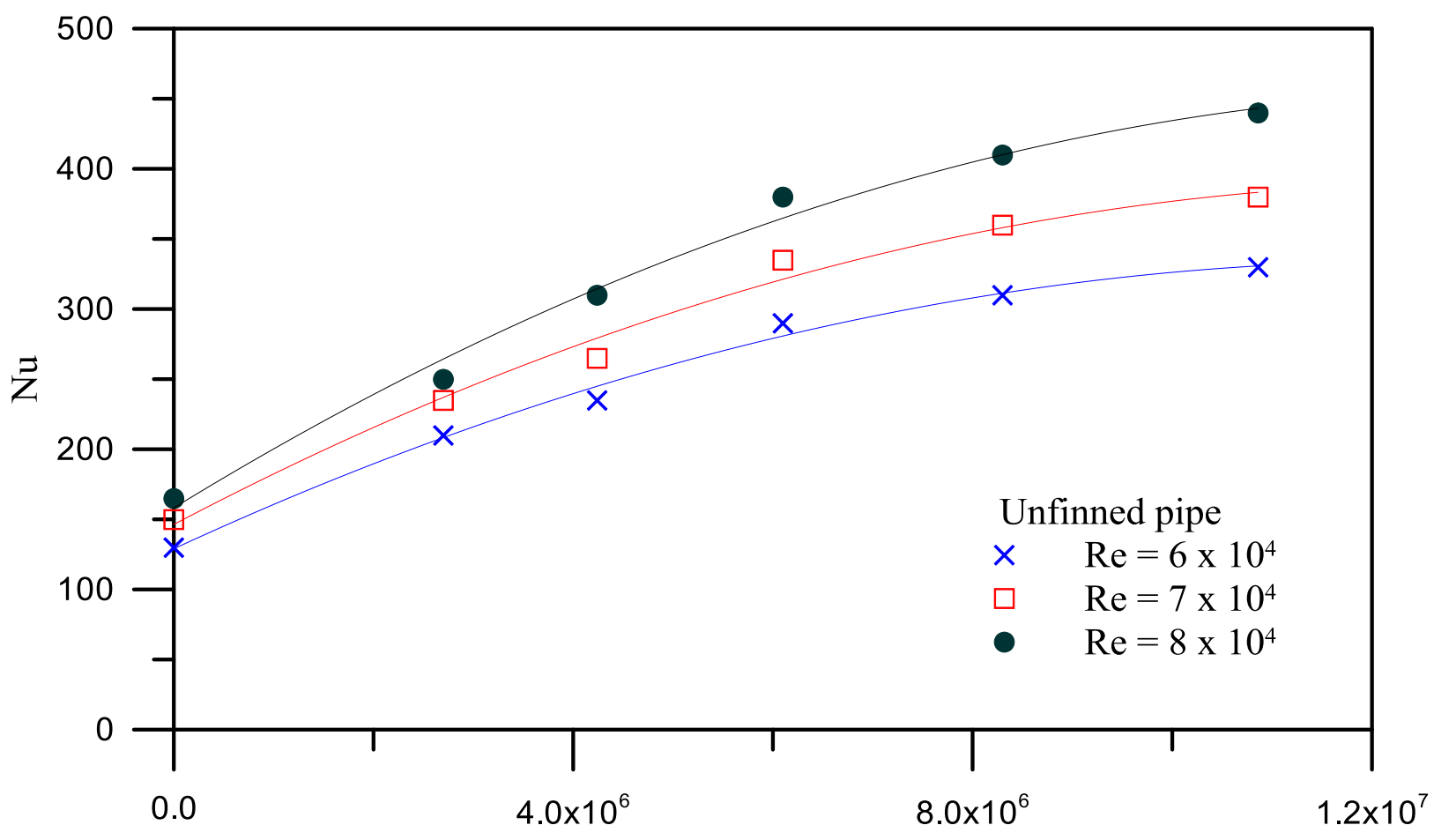

$\mathrm{Ta},(-)$

Fig. 11. Variation of Nusselt number with Taylor number for unfinned pipe at different Reynolds number.

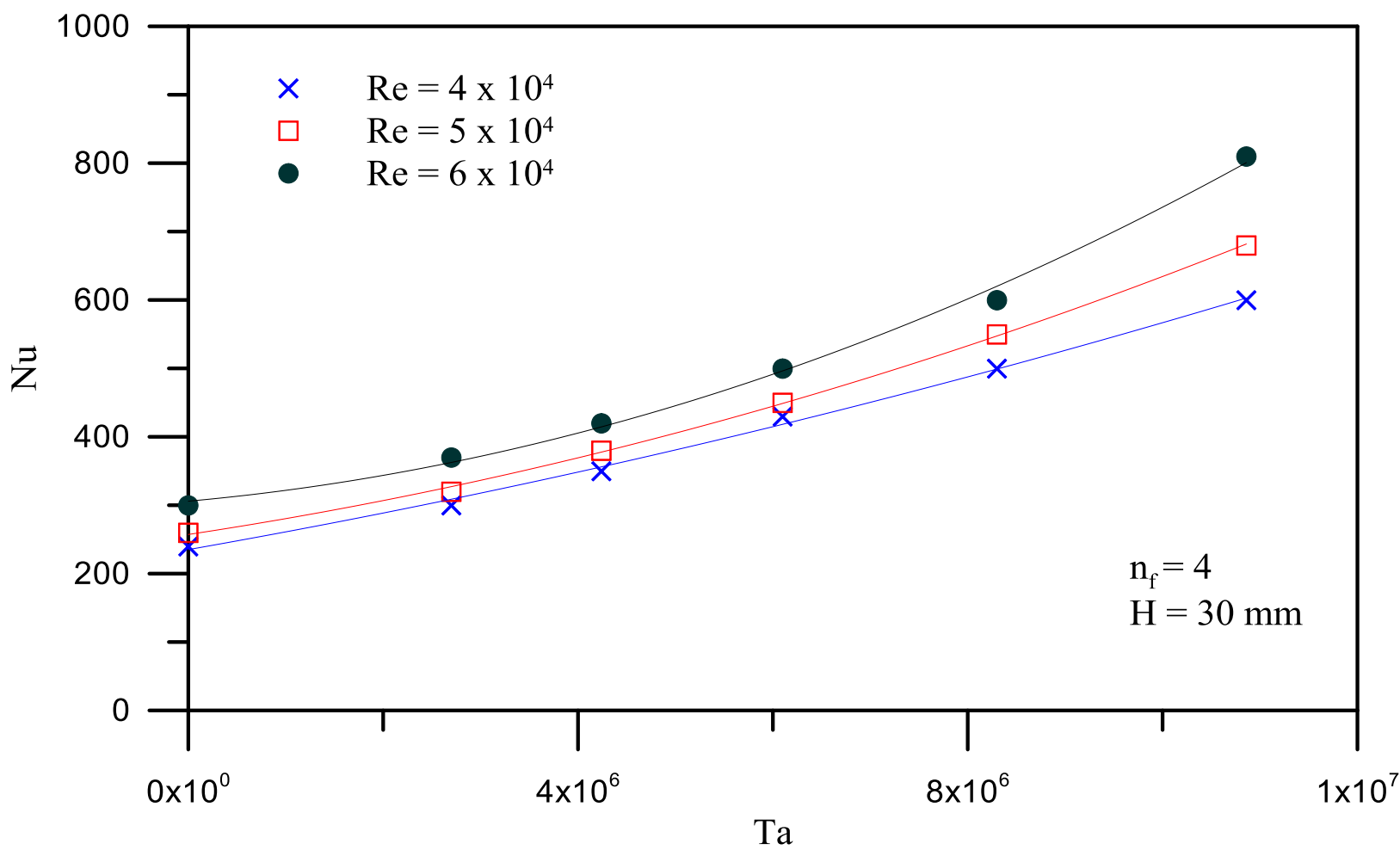

Fig. 12. Variation of Nusselt number with Taylor number at different Reynolds number for 4 fins and height $30 \mathrm{~mm}$. 


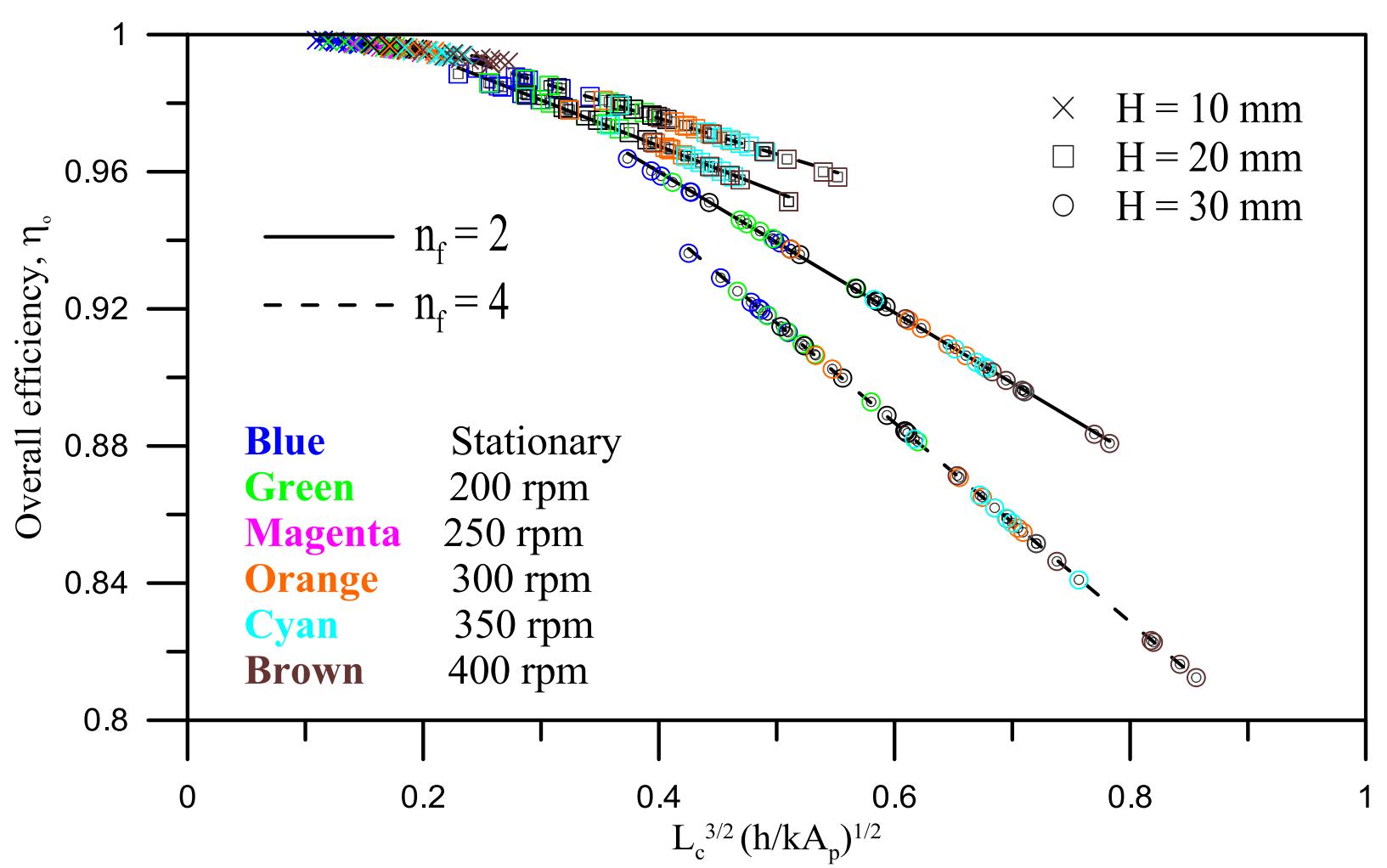

Fig. 13. Overall fins efficiency

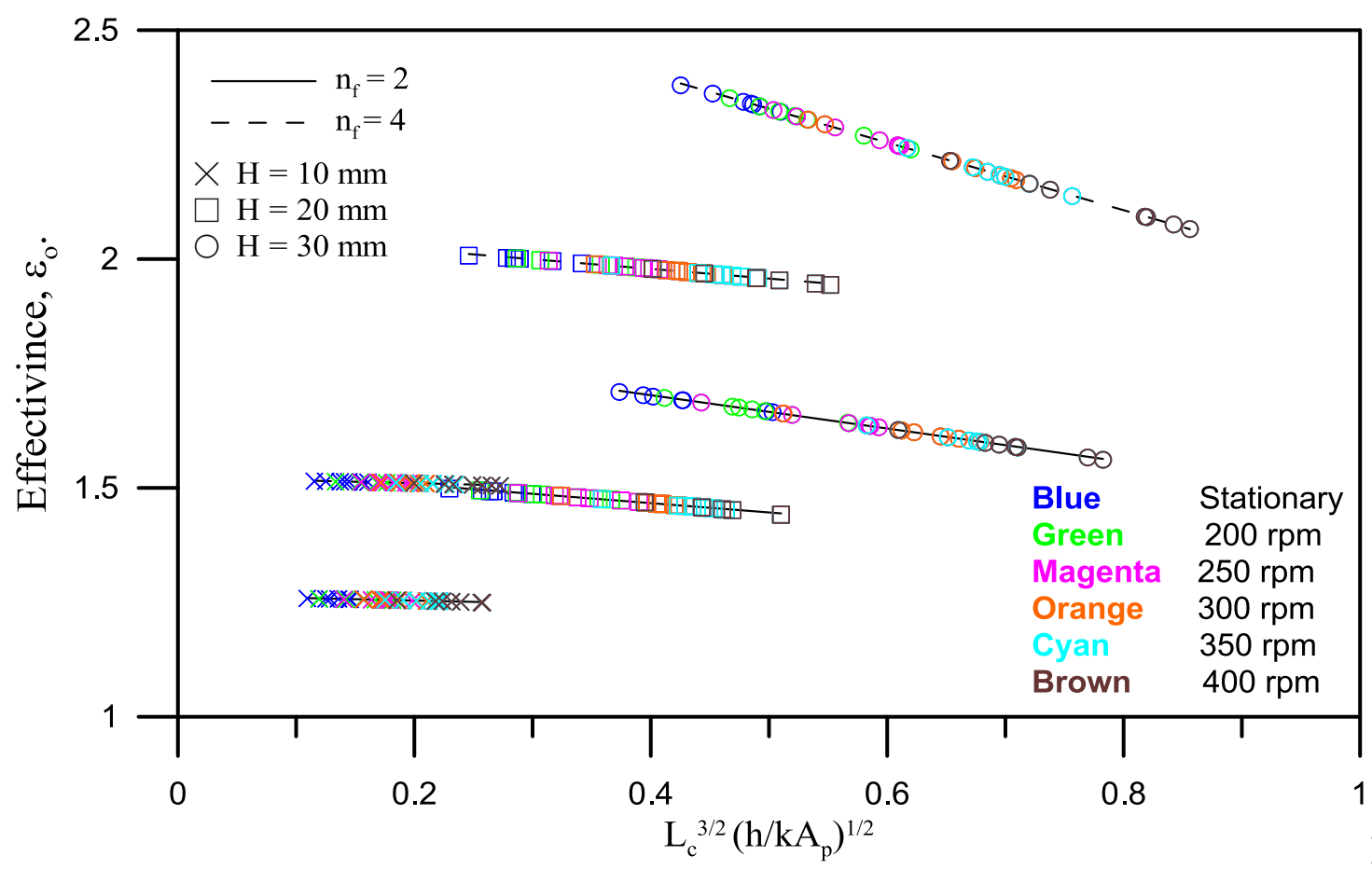

14. Overall fins effectiveness

Fig. 


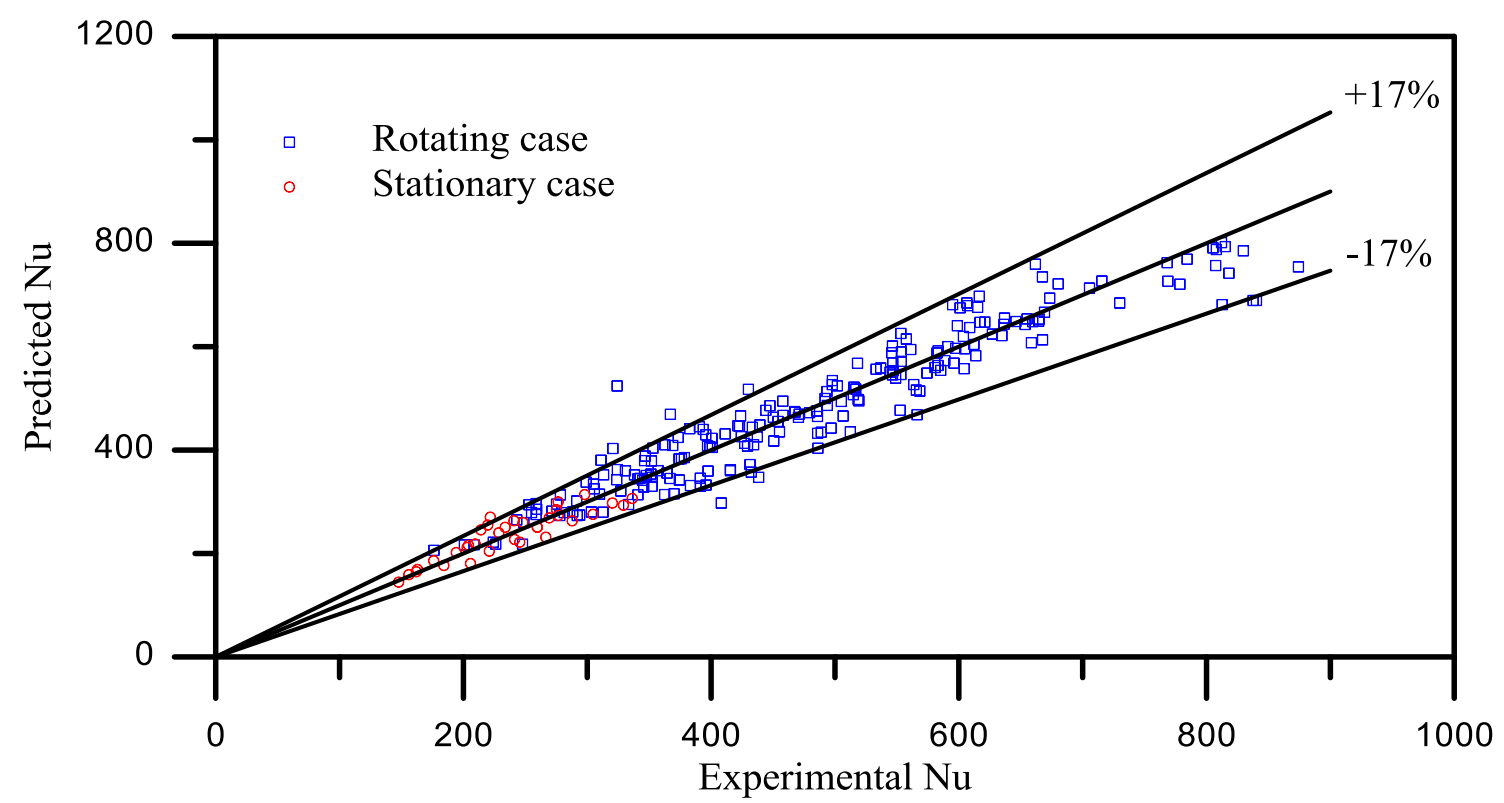

Fig. 15. Predicted Nu versus experimental Nu.

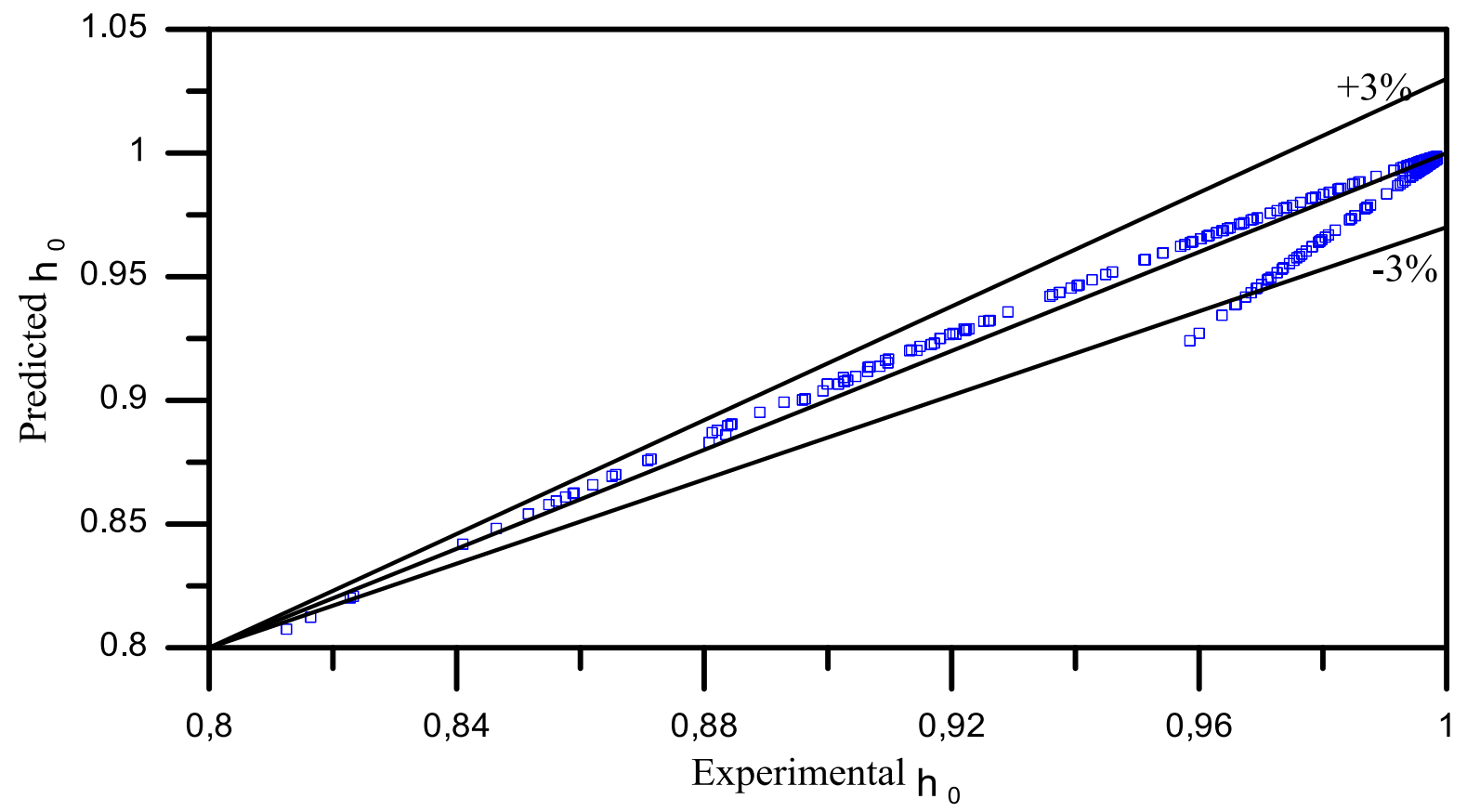

Fig. 16. Predicted $\eta_{0}$ versus experimental $\eta 0$. 